\title{
Differential instructions and interstimulus interval in eyelid conditioning'
}

MARK OMINSKY, DEPARTMENT OF PSYCHOLOGY, DUKE UNIVERSITY, Durham, N. C. $27706^{2}$

In an experiment in which each $S$ received two CS-US intervals and varied instructions, conditioning was retarded in the shorter of the two ISIs by both inhibitory instructions and the within-S experimental design itself. CRs to the longer ISI depended upon specific instructions, but the relationships were quite complex. Poor discrimination was found between the two ISIs as measured by the small difference between CRs to the short ISI CS and responses in the short ISI CR range for the long ISI CS.

This experiment concerns the effects of inhibitory set in a "within-Ss" experiment where Ss receive two interstimulus intervals and different types of instruction. With the "between-Ss" type of design, it has been found that eyelid conditioning has an optimal interstimulus interval (ISI) of about 500 msec. Many conditioning studies have failed to produce the same effects for between-S and within-S designs, however. Kimble, Leonard, \& Perlmuter (1966) cited several experiments which revealed these differences for either CS or US intensity. Noting that no previous experiments had been performed to investigate the effect of a within-S design on the ISI function, Kimble et al conditioned Ss to two different ISIs, one the optimum $500 \mathrm{msec}$ interval and the other a longer $1200 \mathrm{msec}$ interval, using the classical eyelid procedures. Performances to the two intervals were compared for these Ss as were differences between two other groups given only one interval (either $500 \mathrm{msec}$ or $1200 \mathrm{msec}$ ).

Their results were: (1) there was a significant difference between the $500 \mathrm{msec}$ and $1200 \mathrm{msec}$ conditioning levels for the between-S groups (with $500 \mathrm{msec}$ the assumed optimum being higher); (2) there was no difference between the conditioning levels of the ISIs for the within-S design; (3) Ss who received only one ISI performed at a significantly higher level than those who received two ISIs; (4) for the within-S group the presence of the long ISI had a retarding effect on the development of CRs during the short ISI.

The present experiment served partially as a replication of Kimble et al within-S design using the same ISIs (400 and 1100 msec) as Ominsky (1968) and also to investigate the role of inhibitory and differential inhibitory instructions on conditioning with this type of design.

Method. The Ss were 80 undergraduate students ( 48 males and 32 females) all of whom volunteered to fulfill the requirements of the introductory psychology course. Ss were assigned randomly to one of four groups except that males and females were balanced during the course of the experiment. Each $S$ received two different lights (red and green) which were associated with two CS-US intervals, a short $(.4 \mathrm{sec})$ and a long $(1.1 \mathrm{sec})$. Each group was given different instructions regarding the two lights; the instructions and apparatus were basically the same as those of Ominsky (1968).

The facilitate both (FB) group received facilitatory instructions for both stimuli. The inhibit both (IB) group received inhibitory instructions for both stimuli. The inhibit long (IL) and inhibit short (IS) groups received differential instructions; that is, they were instructed to inhibit their responses while one light was on and relax while the other light was on. IL attempted to inhibit their responses to the stimulus associated with the long CS-US interval only; IS attempted to inhibit responding during the stimulus associated with the short CS-US interval only.

The red and green lights were associated with the long and short ISIs, respectively. The red and green lights were balanced within each group for short and long interval, so that, for example, half of the IL Ss inhibited responses during the red light and the other half inhibited during the green light. The Ss were not told which CS-US interval to inhibit, but merely which color light (red or green) to inhibit.
The $\mathrm{S}$ received his instructions followed by preliminary trials consisting of four CSs (two short and two long) and two USs. One hundred conditioning trials were then administered, 50 at each of the two CS-US intervals.

Results and Discussion. The performances of the four instructional groups are shown in Fig. 1 which plots the mean percentage of CRs to the long $(1.1 \mathrm{sec})$ and short $(.4 \mathrm{sec})$ ISI CSs in blocks of 10 trials.

A three-factor analysis of variance (Case 1 in Winer, 1962) was performed with instructional group as the between-S factor and CS-US interval and blocks of trials as the within-S variables. The analysis was based on the percentage of CRs given to each ISI CS (the latency criteria of $240-425 \mathrm{msec}$ and $660-1125 \mathrm{msec}$ for the short and long ISI CSs, respectively) for each block of 10 trials. The between-S factor of instructional group was significant $(F=$ 5.70 , $\mathrm{df}=3 / 76, \mathrm{p}<.005$ ), indicating that instructions were effective in changing the total conditioning scores of the various groups. Turning to the within-S comparison of ISI, we find that there were significantly more CRs given to the long ISI CS than to the short one $(F=53.09, \mathrm{df}=1 / 304, \mathrm{p}<.001)$. The second main within-S factor, that of blocks of trials, is also significant $(F=$ 24.46, df $=4 / 304, p<.001)$. Since the percentage of CRs increased in blocks of 10 trials, we can say that overall conditioning took place. The only significant interaction was that of instructions by interval $(F=14.76, \mathrm{df}=3 / 304, \mathrm{p}<.001)$.

A more detailed description can be gleaned from an analysis of the simple effects. For percentage of CRs to the long ISI CS (solid lines in Fig. 1), all instructional groups were significantly different from each other, except for the difference between FB and IB (which was marginally significant, $p<.10$ ). The groups from least to greatest percentage of CRs are: inhibit long < inhibit both $<$ facilitate both $<$ inhibit short. For the short ISI CS (dotted lines in Fig. 1) all instructional groups were significantly less than the facilitate both group $(p<.01)$, but the inhibitory groups were not significantly different from each other.

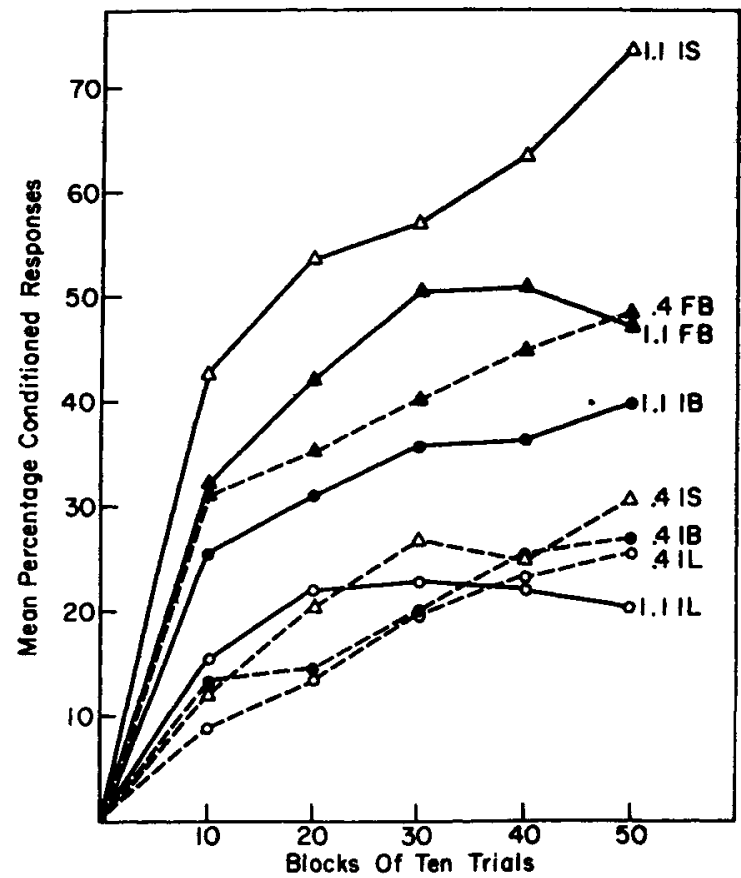

Fig. 1. Percentage of conditioned responses during the short $(.4 \mathrm{sec})$ and long (1.1 sec) ISIs for all groups in blocks of 10 trials. 
The differences between the percentage of CRs given to the long and short ISI CSs were highly significant for IB and IS (F = 12.99, $\mathrm{df}=1 / 76, \mathrm{p}<.01$ and $\mathrm{F}=82.27$, $\mathrm{df}=1 / 76, \mathrm{p}<.001$, respectively), but not for FB or $1 \mathrm{~L}$. There was a highly significant increase in percentage of CRs from the first block of trials to the last for all instruction groups and for both the short and long ISI, indicating that even the poorest groups conditioned.

Many short interval CRs were found within the long ISI in a preliminary inspection of the data. These responses can be considered generalized responses from the short ISI CS which indicate the amount of discrimination between the two intervals so chosen as to have no overlap in CR latency range. Differences between $.4 \mathrm{sec} C R s$ for the $.4 \mathrm{sec}$ ISI CS were compared to $.4 \mathrm{sec}$ criterion CRs during the $1.1 \mathrm{sec}$ ISI CS and analyzed by $t$ tests for the four groups. There were no differences for the FB and IS groups $(t<1, \mathrm{df}=19)$, but there were significant differences for the IB and IL groups $(t=4.24, \mathrm{df}=19, \mathrm{p}<.001$ and $\mathrm{t}=2.24$, df $=19, p<.025)$. Despite the significant differences, the mean percentage differences for those groups were only $4.67 \%$ and $5.67 \%$.

The results of the experiment show that the effect of inhibitory set produced by instructions can influence conditioning greatly. Ss can be conditioned to two different CS-US intervals simultaneously and, further, these intervals can be affected differentially by instructions.

The major findings were derived by looking at the effect of instructions on the two ISIs separately. First, for the $.4 \mathrm{sec}$ ISI we found that the percentage of CRs for all three groups given inhibitory instructions was equal and was significantly below the facilitate both group. Second, the mean percentage of CRs to the 1.1 sec ISI was ordered from highest to lowest as IS $>$ FB $>$ IB $>$ IL; all of these differences were statistically significant except for the marginally significant difference between FB and IB.

The first result seems to be a fairly clear one. All three inhibitory groups were equal despite the fact that the IL group was instructed not to inhibit responding during the short ISI. The fact that short ISI CRs were at such a low level for IL is indicative of a generalized inhibitory set acting on the relatively brief 400 msec ISI. The second result seems quite complex, and any explanation would be very speculative at this point. It must be stressed, however, that groups IL and IS needed to discriminate between the two CSs in order to correctly apply their differential instructional sets. This is contrasted with groups FB and IB who could essentially ignore differences between the two stimuli and still fulfill their instructions.

\section{REFERENCES}

KIMBLE, G. A., LEONARD, T. B. HI, \& PERLMUTER, L. C. Effects of interstimulus interval and discrimination learning in eyelid conditioning using between- and within-Ss designs. Paper delivered at Psychonomic Society meeting, October, 1966.

OMINSKY, M. Instructions and interstimulus interval in eyelid conditioning. Psychon, Sci., 1968, 12, 49-50.

Sci., 1968, 00, 000-000.

WINER, J. Statistical principles in experimental design. New York: McGrawHill, 1962.

\section{NOTE}

1. Based on a dissertation submitted in partial fulfillment of the requirements for the Ph. D. degree at Duke University and supported in part by Research Grant MH-08090 from NIH to Dr. Gregory A. Kimble. The author wishes to thank Dr. Kimble for his support and guidance.

2. Presently at IBM, Endicott, N.Y. 